\title{
Ciudadanía E INMigración: LA NUEVA FRONTERA ENTRE LA PERTENENCIA Y LA EXCLUSIÓN
}

\author{
María Dolores Vargas Llovera
}

Resumen: El concepto de ciudadanía ocupa de nuevo el centro de la reflexión teórica y del debate público sobre todo desde los últimos años del pasado siglo. La sociedad democrática es por excelencia una sociedad fundada en el conflicto y, por lo tanto, la política del futuro inmediato debe orientarse a la elaboración de estrategias para encontrar nuevas modalidades de interacción entre mayorías y minorías que permitan preservar el derecho a las diferencias politicas y culturales de los diferentes grupos, manteniendo a la vezun espacio armónico de convivencia. En este sentido, el concepto de ciudadanía marca las diferencias entre quienes la poseen como normativo para marcar los derechos y obligaciones, no sólo políticos, sino también sociales y culturales, y de quienes no la poseen por el hecho de haber emprendido el camino de la emigración.

Palabras clave: Ciudadanía, inmigración, migraciones, exclusión, segregación.

Enviado a dictamen: 03 de marzo de 2011

Aprobación: 26 de abril de 2011

Revisiones: 1

Dra. María Dolores Vargas-Llovera, Universidad de Alicante, Alicante (España), Correo electrónico: md.vargas@ua.es.
Abstract: The concept of citizenship is once again the center of theoretical reflection and public debate especially from the last years of last century. Democratic society is based on conflict and, therefore, the policy of the immediate future must focus on developing strategies for finding new modes of interaction between majority and minority which preserve the right to political differences and different cultural groups, while maintaining a harmonious living space. In this sense, the concept of citizenship makes the difference between those who possess it as normative to highlight the social and cultural rights and obligations, not only political, and those who do not have it due to take the course of emigration.

Keywords: Citizenship, immigration, migrations, exclusion, segregation.

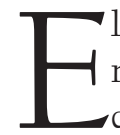
fenómeno de los desplazamientos humanos no es una situación nueva en el mundo; así, desde el inicio de los tiempos, las personas se han movido de un sitio a otro por diferentes motivos: guerras, hambrunas, cuestiones religiosas, etcétera. En la actualidad, y como una de las consecuencias de la globalización, los flujos migratorios afectan a todos los rincones del planeta con unas notas definitorias diferentes a otros momentos de la historia. Castel (2002) resume muy claramente el fenómeno actual: 
[...] la migración internacional es parte integrante de la mundialización que puede ser definida como una ampliación, profundización y aceleración de la interconexión mundial en todos los aspectos de la vida social contemporánea. El principal indicador de la mundialización es el rápido crecimiento de los flujos fronterizos de todo tipo: finanzas, comercio, ideas, contaminación, productos mediáticos y personas...

Sin embargo, esas mismas fronteras se vuelven férreos muros de separación y de segregación entre mundos antagónicos: el opulento Norte y el desestructurado Sur; muros que en ocasiones se tiñen de sangre de los seres humanos que pretenden buscar la subsistencia del llamado paraíso occidental.

Los movimientos migratorios, fundados en diferentes motivaciones, generan nuevas realidades sociales y escenarios políticos. El fenómeno migratorio en todo momento implica una situación de extrañamiento e incertidumbre, un cierto estado de ansiedad provocado por el miedo a lo desconocido, aunque también por el miedo a que lo conocido no sea lo único válido, lo único existente, lo único verdadero. El intercambio cultural, aun en sus mínimos niveles de roce, de convivencia, conlleva un cierto conocimiento de la existencia de lo diferente. Diferentes maneras de sentir, de pensar, de ser, de reaccionar, de afrontar la vida, encuentran eco en diversas plataformas sociales e ideológicas que encuentran perfecta justificación en diferentes procesos históricos y culturales contenidos en el desarrollo de la civilización humana. Conlleva en definitiva el reconocimiento implícito o explícito de la pluralidad, un elemento o característica social no demasiado impulsada en las sociedades. En efecto, no siempre la diversidad cultural se encuentra en la base de la moderna sociedad democrática que busca reconocer las identidades culturales de los grupos y sus derechos en cuanto ciudadanos.

Las migraciones actuales están directamente relacionadas con la compleja dimensión del concepto de ciudadanía, restringido y de consecuencias, en muchos casos, trágicas en todos los países receptores de inmigrantes que operan ya no sólo en la exclusión, sino también en la desigualdad social y cultural; es decir, nos encontramos con sociedades fragmentadas y divididas ante la condición de ciudadano, provocando procesos de diferenciación en el ejercicio de los derechos y deberes, convirtiéndose estas "ciudades multiculturales" en una división dual de ciudadanos/no ciudadanos (Vargas, 2007).

Lo que va a determinar que una persona tenga unos derechos o no, que pueda o no cruzar unas fronteras, tiene que ver con el concepto de ciudadanía. Este es un concepto político, evidentemente, ligado a los derechos políticos y sociales de los miembros de un Estado, lo que tradicionalmente ha denotado la adscripción de una persona a un Estado nacional, y a partir de ahí la distinción entre nacionales y extranjeros, una distinción que a juicio de Walzer (1993) se convierte en un instrumento de exclusión.

En nuestras sociedades existen mecanismos estructurales de carácter jurídico, social, económico, político, de género, etcétera, y formas culturales arraigadas que impiden a sectores de la población el disfrute real de la condición de ciudadanía plena. Esto se muestra de modo especialmente dramático para los inmigrantes. Tengan o no "papeles", se ven reducidos jurídica, social y culturalmente a "no-personas", son percibidos como amenaza cultural o como mercancía supeditada a "intereses nacionales" y no como personas sujetos de derechos. "Diferenciación" e "inferiorización" se alían para sustentar una discriminación en el plano de los derechos ciudadanos.

Delgado (2003) sugiere, con gran realidad, que la línea divisoria puede estar situada debajo del sistema de estratificación social, de manera que la sociedad divide entre "los de aquí" y "los de fuera"; de tal forma, estos últimos se convierten en marginados a los que se les puede sobreexplotar y convertir en culpables de males sociales como la delincuencia o el paro. 
Por lo tanto, el inmigrante está condenado a habitar a perpetuidad la fase preliminar de un rito de paso, este espacio que hace de aquel que lo atraviesa alguien que "no es ni una cosa ni otra", pero que puede ser simultáneamente las dos condiciones entre las que transita: "de aquí", "de fuera", aunque nunca de una forma integral. Ha perdido sus señas de identidad, pero aún no ha recibido plenamente las del iniciado.

Hablar de ciudadanía en las migraciones transnacionales es hablar de ciudadanía diferenciada, encontrándonos en una situación de cambio, de separación, de exclusión ante una realidad migratoria importante, a pesar de reconocer que los Estados tienen el derecho soberano de formular sus propias leyes asignando las condiciones jurídicas de los individuos. Esto nos lleva a una condición de ciudadanía restringida en que la problemática se nos revela en el momento en que nos planteamos si la persona emigrante está comprendida o no en el perfil y definición de ciudadano o ciudadana (Vargas y Escartín, 2006).

El concepto de ciudadanía es dinámico. Como aporta Espín (2007), esta apreciación supone contemplar la ciudadanía tanto como un estatus - lo cual incluye aspectos jurídicos y legales - pero también como un proceso que implica la plena participación en el interjuego social y político. En definitiva, la consideración de ciudadano o ciudadana es ser -y sentirse - miembro de una comunidad, lo que confiere derechos y deberes. Es tanto un estatus -o una identidad - como una práctica o proceso de formar parte del mundo social a través de la puesta en práctica de esos derechos y deberes (Escartín y Vargas, 2008: 35-52)

De acuerdo con Cortina (1997), consideramos que el concepto de ciudadanía se genera desde la dialéctica interno/externo, desde esa necesidad de unión con los semejantes que comporta la separación de los diferentes. Esta situación, en las sociedades llamadas occidentales, se percibe como un permanente conflicto. Cualquier noción de ciudadanía que desea responder a la realidad actual debe estar totalmente ligada no sólo a la ciudadanía nacional sino además a una ciudadanía mucho más universal tratando, de este modo, de buscar una ciudadanía o identidad más integrativa y menos disgregadora. Marshall (1998). ya concibió la ciudadanía desde la perspectiva de que ciudadano es aquel que en una comunidad política no goza sólo de derechos civiles, en los que no exclusivamente existen derechos políticos, sino también de derechos sociales. En consecuencia, la ciudadanía social está ligada directamente a los derechos sociales, cuya protección vendría o tendría que estar garantizada por el Estado nacional. Una situación de difícil apuesta ante la transnacionalización existente, es decir, el orden internacional está inmerso en grandes transformaciones (Basail y Vargas, 2006).

La noción de ciudadanía nos lleva a deducir que en las sociedades receptoras de inmigrantes la ciudadanía está fragmentada y limitada. El inmigrante se siente ciudadano de su país, pero no ciudadano del país receptor a pesar de que se encuentre en una situación administrativa totalmente regularizada; se debate entre su lugar de nacimiento y su lugar de vida. De acuerdo con De Lucas (2004: 5-10), los inmigrantes podrían poseer no sólo derechos civiles, económicos, sociales y culturales, sino también en determinadas condiciones el conjunto de derechos políticos bastaría vincularlos a la residencia y no a la ciudadanía-nacionalidad. Pero la realidad es otra, los inmigrantes están permanentemente amenazados porque no existe un replanteamiento de la ciudadanía. Basail y Vargas (2006) han considerado que sentirse y saberse ciudadano es un principio fundamental para entender la realidad de la ciudadanía. Pero el sentido de ciudadanía es político, es decir, un individuo se siente ciudadano en virtud de sentirse de pleno derecho, política y administrativamente, de una comunidad, sociedad o país, y que en su inconsciente debe una adhesión de lealtad hasta el fin de sus días. De esta manera, se entiende que este reconocimiento a una comunidad política va unido al estatuto de ciudadano al mismo tiempo que constituye un factor de identidad. 
No podemos olvidar que el ser ciudadano pasa por las limitaciones territoriales de los Estados nación donde todos los individuos nacidos dentro de sus fronteras son considerados sus ciudadanos con sus derechos y deberes en el contexto social, político y cultural, es decir, en el contexto colectivo donde las personas se definen dentro de sus límites y se identifican sintiéndose integrados dentro de su Estado que, al mismo tiempo, les ha reconocido como ciudadanos. Tal situación era casi inamovible mientras estos Estados nación formaban sociedades uniétnicas. En el momento que se integran ciudadanos de otros países se convierten en sociedades poliétnicas, por lo tanto, estos Estados se convierten en multiculturales, con diferentes identidades y diferentes clases de ciudadanos, llegando a la jerarquización dentro del contexto de ciudadanía.

En todas las sociedades, la presencia de extraños conlleva un cambio en la percepción tradicional del término ciudadanía, causando fragmentaciones y conflictos ante la determinación de tener que aceptar a nuevos individuos que se encuentran en los límites o fuera de ellos de derechos y obligaciones que marque la sociedad. A partir de estos presupuestos podemos realizar un recorrido sobre los conceptos o teorías que hoy se debaten.

En 1994 el autor austriaco Rainer Bauböck escribió el libro Transnational Citizenship y acuñó el concepto de ciudadanía transnacional, que representa un nuevo significado de ciudadanía basado en el hecho de que individuos de otras nacionalidades pueden llegar a incorporarse como miembros de otras sociedades compartiendo derechos y obligaciones. Esta situación de justicia no llega a ser una realidad en las actuales migraciones, pero al mismo tiempo no debe pasar desapercibido que en la situación de la actual inmigración existe la necesidad de que la condición de ciudadanía se transforme y deje de ser un factor de exclusión y se convierta en un factor de inclusión pasando, de esta manera, a ciudadanías pluriculturales dentro de una igualdad y sin derechos diferenciados (Vargas, 2007).

Las nuevas aportaciones, tal como lo referimos en Vargas (2007), sobre el conjunto del concepto de ciudadanía se encuentran en posiciones de debate. Iris Marion Young (1990) parte de que los espacios sociales no sólo deben ser compartidos por individuos iguales sino al mismo tiempo por grupos diferentes caracterizados por su propia identidad, con el fin de reafirmar su ciudadanía y el bien común desde sus diferencias y formas particulares sin que la exclusión forme parte del entramado social. Los inmigrantes como grupo de diferentes son excluidos por sus situaciones de migrantes económicos y por su propia identidad social y cultural. Young considera que la ciudadanía ha de tener en cuenta estas situaciones de diferencia, es más, habla de "ciudadanía diferenciada", y según Kymlicka y Norman (1996) desde esta perspectiva los miembros de ciertos grupos serían incorporados a la comunidad no sólo como individuos sino también a través del grupo, y sus derechos dependerían en parte de su pertenencia al grupo. Pero desde el punto de vista ortodoxo, la ciudadanía es por definición una manera de tratar a la gente como individuos dotados de derechos iguales ante la ley. De ahí que la organización de la sociedad sobre la base de derechos o pretensiones derivadas de la pertenencia a determinado grupo se opone radicalmente al concepto de sociedad basado en la idea de ciudadanía de Porter, en 1987, citado por Kymlicka y Norman. ${ }^{1}$

\section{La exclusión antes que la pertenencia}

El concepto de exclusión social surgió en los años 70 en Francia entendido como la ruptura de vínculos sociales de la sociedad. Su fundador fue R. Lenoir, quien lo desarrolló en su libro Les exclus: un Français sur Dix, en 1974. Es un proceso mediante el cual los individuos o grupos son total o parcialmente excluidos de una participación plena en la sociedad en la que viven. El concepto defendía en su contenido el significado de los nuevos 
problemas sociales, refiriéndose a los sectores más desfavorecidos y afectados de la sociedad, por lo tanto, podemos afirmar que la exclusión como manifestación es el resultado de la estructuración de la sociedad, es decir, de una determinada estructura social y, como afirma Bel (2002), es la propia organización social la que elabora en su interior lo que llama "poblaciones sobrantes". Por consiguiente, hablar de exclusión social es expresar y dejar constancia de que el tema no es tanto la pobreza y las desigualdades en la pirámide social sino en qué medida se tiene o no un lugar en la sociedad, marcar la distancia entre los que participan en su dinámica y se benefician de ella, y los que son excluidos e ignorados fruto de la misma dinámica social. También, y no podemos obviarlo, supone alertar sobre los efectos en la evolución de la sociedad y los riesgos de ruptura de la cohesión social que conlleva, así como todo un proceso de agresividad y violencia personal y social que desencadena, como dice con contundencia Bel (2002), un germen de violencia en su triple componente: institucional, popular, represivo. El carácter procesual y dinámico es la nota más distintiva; la exclusión social no es tanto una situación, sino un proceso de diversa intensidad según personas y grupos. Pero la exclusión refleja, así lo han afirmado autores como García Canclini (1995), Castel (1997) o Alonso (1999), la pérdida de la condición de ciudadanía.

La exclusión es identificada por la precariedad en el trabajo, se nutre de trabajos informales, sumergidos, que aíslan a quienes los realiza llevándoles hacia el camino de la marginación, que al mismo tiempo les lleva al distanciamiento del resto de la sociedad. La exclusión social de los inmigrantes parte de razones estructurales. La mayoría de los inmigrantes llegan a los países de recepción de forma irregular, y esta irregularidad va unida a la aceptación de trabajos de categoría baja o muy baja y mal remunerados, a la vez rechazados por los autóctonos, lo que les lleva a ocupar espacios segregados en barrios marginales donde las viviendas se pueden calificar de infraviviendas. Ya apuntó Abad
(1993), que los trabajos o la actividad económica que surgen a partir de las migraciones actuales y en los que se ve inmerso el trabajador inmigrante lo empujan hacia la marginalidad en una sociedad donde los prejuicios y el racismo se encuentran en la realidad cotidiana. Como entiende Allport (1954) las actitudes hostiles hacia algunas personas que pertenecen a grupos concretos fomentan los prejuicios simplemente por pertenecer a estos grupos, es decir, que la pertenencia a un segmento social incluye la relación de prejuicio y esta relación va unida a la exclusión social o, dicho de otra forma, los grupos que se encuentran dentro de la exclusión social son motivo de prejuicio; lo que lleva, al mismo tiempo, hacia una estigmatización de estos individuos y a la formación de estereotipos negativos que las sociedades de recepción acuñan, porque divergen de las normas y valores dentro del más puro etnocentrismo. Esto tampoco significa que la tendencia natural e universal del etnocentrismo sólo surja dentro de los individuos que forman las sociedades de acogida, este sentimiento es parte del ser humano. Pero en las situaciones de las poblaciones inmigrantes y el enfrentamiento entre "nosotros" y "ellos" favorece dicha realidad.

La exclusión se produce porque las migraciones en las sociedades receptoras pasan por grandes etapas dentro de largos procesos que funcionan con un gran dinamismo por el flujo continuo de llegada y de grandes dificultades en que se encuentran las ciudades para poder recibir y asentar a tanta población. Desde que el inmigrante llega a la ciudad hasta que estabiliza un lugar de residencia pasa por una serie de etapas relacionadas con la mejora de sus condiciones económicas y legales. Fullaondo (2007) realiza una clasificación de las etapas por las que pasan los inmigrantes a partir de diferenciar tres etapas migratorias de "tipo ideal", en el sentido weberiano del término: la llegada, el asentamiento, la estabilización. Considera, también, que el inmigrante que acaba de llegar a la ciudad se encuentra en la etapa inicial, generalmente es una inmigración individual y con un gran desconocimiento de la sociedad que ha 
llegado: de las reglas y pautas de comportamiento. La gran mayoría de las veces se encuentra en una situación irregular, por lo tanto si encuentra trabajo es muy precario y si accede a una vivienda siempre es mediante el subarriendo de una habitación o una cama - las llamadas "camas calientes - o hacinado en una vivienda, siempre dependiente del apoyo de las redes sociales o funcionales de la comunidad de origen. En esta etapa migratoria los inmigrantes se encuentran en una situación de precariedad y vulnerabilidad máxima.

La siguiente etapa, según Fullaondo (2007), es la de asentamiento. El inmigrante tiene un mayor conocimiento de las reglas y procedimientos de la sociedad de acogida. Sigue accediendo a trabajos precarios, aunque ya puede buscar mejores condiciones. La vivienda se consigue mediante el subarriendo, no obstante en mejores condiciones. La dependencia de las redes son menores, pero aún existen, y pueden pasar a ser parte activa de las mismas.

La tercera etapa, de estabilización, se produce una vez que el inmigrante ha normalizado su situación legal y residencial después de demostrar el arraigo en la sociedad de acogida de tres años. Conseguido esto y si se encuentra en una situación regular puede proceder al reagrupamiento familiar. Accede al mercado laboral de forma "normalizada" dentro de sus capacidades laborales, pero posiblemente condicionada por la discriminación por razón de origen. Puede acceder a una vivienda mediante alquiler o incluso a la compra de una vivienda.

Estas situaciones son los pasos que, con mucho tiempo incluso años, lleva la dinámica de los nuevos inmigrantes. En la medida en que los inmigrantes se encuentren en una de estas etapas del proceso migratorio, sus condiciones y su relación con la sociedad de acogida variarán y, por lo tanto, la problemática del propio inmigrante también. Cuando la mayor parte de los inmigrantes se encuentra en la etapa de estabilización entonces la sociedad define su configuración. Es en esta etapa cuando podemos comenzar a concluir cuál es el grado de segregación de los diferentes colectivos de inmigrantes en la sociedad (Fullaondo, 2007).

En esta situación, para que los individuos y los grupos sean reconocidos como excluidos se partirá de una negación al acceso de oportunidades, y tal como apuntan Buvinic, Mazza y Pungiluppi (2004), la exclusión se produce si la pertenencia a un cierto grupo tiene un impacto considerable sobre el acceso a oportunidades que cuenta el individuo, y si las interacciones sociales entre grupos ocurren en el marco de una relación de autoridad/subordinación. Por consiguiente, la exclusión se desarrolla a través de diversos intercambios entre instituciones y sociedad que les niegan la participación en el entramado social. En este sentido, podemos hablar de que la exclusión es una cuestión de la sociedad. Es el conjunto social el que participa en la división de los que consideran que son incluidos o excluidos $y$, en el caso que nos ocupa, la inmigración es un elemento conflictivo que produce rechazo y se convierte en el ojo del huracán de la intolerancia

\section{Ciudadanía y migración: reflexiones}

Más allá de las posiciones teóricas aplicables en sus diferentes apartados o en su conjunto, no podemos sustraernos al hecho de que el tema de la ciudadanía se encuentra estrechamente ligado a los actuales flujos migratorios que aportan una dinámica aperturista al concepto de ciudadanía, al tener que hablar de un nuevo modelo que dé paso a la incorporación de los inmigrantes desde una óptica pluralista e inclusiva. No obstante la legalidad política que sustenta el actual concepto de ciudadanía nos debe conducir irremediablemente a no olvidar que la condición de ser ciudadano comporta otras dimensiones que no son las estrictamente basadas en la legalidad que los Estados determinan. De esta manera, ante el incremento de los flujos migratorios es preciso hacer comprender la noción de ciudadanía en un sentido amplio que vaya más allá de las estructuras 
rígidas que hasta ahora han marcado este concepto; además, es necesario plantearse que el fenómeno migratorio forma parte del entramado social de nuestros países y que es una realidad que aflora cada vez con más persistencia, destacándose la exclusión política, legal, social y cultural de una población extranjera que no es reconocida con los mismos derechos que los ciudadanos nacionales (Vargas, 2007).

La ciudadanía es un estatus, un reconocimiento jurídico y social de los individuos. Todos somos iguales dentro de los límites de una sociedad dada, pero la exclusión de los que no forman parte de ella es casi inevitable. Los nuevos replanteamientos vienen dados por la presión de los flujos migratorios, las poblaciones de inmigrantes cada vez están más afianzadas para permanecer de forma definitiva, la cuestión es el reconocimiento de estas personas dentro del marco de las sociedades receptoras. Pero en estas sociedades y estas poblaciones que se encuentran en situaciones de determinado grado de exclusión contemplamos de forma directa y destacada que el concepto de ciudadanía no acostumbra a ir unido.

Tener conciencia de esta realidad sociocultural y política nos conduce a un camino discriminatorio donde el estatus de inmigrante degenera a un nuevo peldaño de la estructura social, que lo podríamos llamar una nueva clase social marginada, porque se encuentra en los márgenes sociales, culturales, económicos y políticos. El inmigrante no posee ninguno de estos derechos, se le niega la legitimidad social y la concesión de cualquier derecho social y político-jurídico. Esta negatividad va unida a la pérdida, en las sociedades de acogida, de su ciudadanía que por derecho tiene en su país de origen. Una vez pasa el umbral de "su" nuevo país, deja de ser ciudadano, pasa a engrosar las filas de las personas que se encuentran dentro de las migraciones donde los derechos político-sociales están jugando entre la ilegalidad/irregularidad y la legalidad/regularidad.

No podemos hablar de una unión perfecta entre los derechos que conlleva el ser ciudadano. El derecho a la ciudadanía queda bien claro que está reservado para los nacionales de un Estado nación. Mirándolo desde el prisma de las migraciones, la categoría de ciudadanía es excluyente. Los inmigrantes son excluidos del reconocimiento de los derechos y de la legitimidad social y jurídica de la sociedad de acogida, es decir, las sociedades se dividen entre los que pueden patentizar la condición de ciudadanos y los que no la pueden alcanzar y se ven privados de ella. Lo que significa que la identificación de ciudadanía conlleva una fragmentación social, una diferenciación que consolida una exclusión social y jurídica en unos nuevos espacios sociales y en nuevas marcas territoriales (Vargas, 2007).

La ciudadanía, siguiendo a De Julios (2004), se convierte gradualmente en un estamento privilegiado frente a la caterva de desposeídos, marginados y excluidos que invaden las fronteras del llamado mundo occidental y, como apunta De Lucas (1999), hay que romper el "círculo cerrado de la ciudadanía entendida como fortaleza" y abrir paso a un nuevo sujeto social que pugna por sus derechos.

En las actuales sociedades multiculturales, donde las migraciones son masivas, el estatus de ciudadanía, y referenciando a De Julios (2004), no puede descansar ya de forma exclusiva sobre la identificación entre nacional o ciudadano. En esta época de avalanchas humanas, la ciudadanía debe adquirir nuevas formas si no queremos que acabe siendo una categoría excluyente e insolidaria; la realidad nos la exponen acertadamente Stephen Castles y Alastair Davidson (2000) cuando dicen:

Millones de personas están despojados de derechos porque no pueden ser ciudadanos en el país de residencia. Aún más son aquellos que tienen el estatus formal de miembros del Estado nacional pero carecen demuchos delos derechosque habitualmentesepiensa que derivan de esta condición. Fronteras porosas e identidad múltiple erosionan las ideas de pertenencia cultural que constituyen el acompañamiento necesario de la pertenencia política. Hay cada vez más

54 Revista LiminaR. Estudios sociales y humanísticos, año 9, vol. IX, núm. 1, junio de 201l, San Cristóbal de Las Casas, Chiapas, México. ISSN: 1665-8027 
ciudadanos que no pertenecen, y esta circunstancia debilita a su vez la base del Estado nacional como lugar central de la democracia.

\section{Notas}

${ }^{1}$ Kymlicka W. y Norman, W. 1996 "El retorno del ciudadano. Una revisión de la producción reciente en teoría de la ciudadanía", en La Política núm. 3, citado en Buenos Aires 1997.

\section{Bibliografía}

Abad, L. V., A. Cucó y A. Izquierdo (Eds.) (1993), Inmigración, Pluralismo y Tolerancia, Madrid: Editorial Popular.

Allport, G. W. (1954), The nature of Prejudice, AddisonWesley: Reading.

Alonso, L. E. (1999), Trabajo y ciudadanía, Madrid: Editorial Trotta.

Appadurai, A. (2001), La modernidad desbordada. Dimensiones culturales de la globalización, Buenos Aires: F.C.E.-Trilce.

Basail, Alain y María Dolores Vargas (2006), "Ingobernabilidad de las fronteras: comparación de dos puertas continentales: España y México", en Lima, Actas del Congreso de las Américas.

Bel Adell, C. (2002), "Exclusión social: origen y características", en Ponencia en el curso: Formación específica en Compensación Educativa e Intercultural para Agentes Educativos, Murcia.

Buvinic, M., J. Mazza y J. Pungiluppi (2004), Inclusión social y desarrollo económico en América Latina, Colombia: Alfaomega.

Cachón, L. (2002), "La formación de la 'España inmigrante': mercado y ciudadanía”, en Revista Española de Investigaciones Sociológicas, núm. 97, pp. 95-126.

Castel, R. (2002), La metamorfosis de la cuestión social. Una crónica del salariado, España: Paidós Ibérica.

Castells, M. (1998), End of Millenium, Maldem, Massachusetts: Blackwell.
Castles S. y A. Davidson (2000), Citizenship and Migration. Globalization and the Politics of Belonging, Londres: Macmillan.

Cortina, A. (1997), Ciudadanos del mundo: hacia una teoría de la ciudadanía, Madrid: Alianza.

De Lucas, J. (1999), "El futuro de la ciudadanía en la UE: ¿Es posible hablar de ciudadanía multicultural?", en Martín, e. Y De la Obras, S: (eds.), Repensando la ciudadanía, Sevilla: Fundación El Monte.

De Lucas, J. (2004), "Perplejidades ante la Constitución Europea", en Jueces para la Democracia. Información y debate, núm. 50, pp. 5-10.

Delgado, M. y otros (2003), Exclusión social y diversidad cultural, Donostia: Tercera Prensa.

Escartín, M.J.y M. D. Vargas (2008), “Mujer, inmigración, Trabajo y ciudadanía: empoderando a las mujeres", en Ex aequo. Revista da Associaçao Portuguesa de Estudios sobre las Mulheres,. núm. 17, Estoril (Portugal): Afrontamento, pp. 35-52.

Espin, J. V. (2007), "Ciudadanía, Multiculturalidad y Género", en Eduardo Soriano (coord.), La mujer en la perspectiva multicultural, Madrid: La Muralla.

Fullaondo, A. (2007), "La segregación residencial Valoraciones e indicadores", en http:/www.arquisocial. org/tiki-download file.php?fileId=171.

García Canclini, N. (1995), Consumidores y ciudadanos, México: Editorial Grijalbo.

Julios, Alfonso de (2004), "La Paradoja de la Ciudadanía. Inmigración y Derechos en un mundo Globalizado", en Revista Justicia, Migración y Derecho, Madrid: Dykinson.

Kymlicka, W. (1996), Ciudadanía multicultural: una teoría liberal de los derechos de las minorías, Barcelona: Paidós.

Kymlicka W. y W. Norman (1996), "El retorno del ciudadano. Una revisión de la producción reciente en teoría de la ciudadanía”, en La Política, núm. 3, Buenos Aires.

Marhsall, T. H. y T. Botttomore (1998), Ciudadanía y clase social, Buenos Aires: Losada. 
Nair, S. y J. De Lucas (1998), El desplazamiento en el mundo. Inmigración y temáticas de identidad, Madrid: IMSERSO.

Vargas Llovera, María Dolores (2007), “Ciudadanía transnacional o la negación de la ciudadanía: los inmigrantes un debate abierto", en Actas de la VII Reunião, Porto Alegre, Brasil: Antropológica do Mercosul-RAM.

Vargas Llovera, María Dolores y A. Cabral (2007), "Inmigración, transnacionalismo y segregación urbana: espacios de desigualdad social", en Ponencia en III Jornadas de Antropología Urbana: Ciudades globales y culturas locales, Bilbao.

Vargas Llovera, María Dolores y M. J. Escartín (2006), "Mujer inmigrante y ciudadanía: una realidad basada en la exclusión", en Actas del Congreso de las Américas, Lima.

Walzer, M. (1993), Las esferas de la justicia. Una defensa del pluralismo y de la igualdad, México: Fondo de Cultura Económica.

Young, I. M. (1990), La justicia y la política de la diferencia, Madrid: Cátedra. 